\title{
A comprehensive review of hip labral tears
}

\author{
Megan M. Groh · Joseph Herrera
}

Published online: 7 April 2009

(c) The Author(s) 2009. This article is published with open access at Springerlink.com

\begin{abstract}
The hip labrum has many functions, including shock absorption, joint lubrication, pressure distribution, and aiding in stability, with damage to the labrum associated with osteoarthritis. The etiology of labral tears includes trauma, femoroacetabular impingement (FAI), capsular laxity/hip hypermobility, dysplasia, and degeneration. Labral tears present with anterior hip or groin pain, and less commonly buttock pain. Frequently, there are also mechanical symptoms including clicking, locking, and giving way. The most consistent physical examination finding is a positive anterior hip impingement test. Because of the vast differential diagnosis and the need for specialized diagnostic tools, labral tears frequently go undiagnosed during an extended period of time. Evaluation usually begins with plain radiographs to assess for dysplasia, degeneration, and other causes of pain. While magnetic resonance imaging (MRI) and computed tomography scans are unreliable for diagnosis, magnetic resonance arthrography (MRA) is the diagnostic test of choice, with arthroscopy being the gold standard. Typically, treatment begins conservatively with relative rest and nonsteroid anti-inflammatory agents, with physical therapy (PT) being controversial. Often, surgical treatment is necessary, which entails, arthroscopic debridement of labral tears and surgical repair of associated structural problems.
\end{abstract}

Keywords Hip · Labrum · Labral tear

$\begin{array}{ll}\text { Abbreviations } \\
\text { OA } & \text { Osteoarthritis } \\
\text { FAI } & \text { Femoroacetabular impingement }\end{array}$

M. M. Groh $(\bowtie)$ J. Herrera

Physical Medicine \& Rehabilitation, Mount Sinai Hospital, New York, NY, USA

e-mail: yankegir18@yahoo.com
DDH Developmental dysplasia of the hip

MRA Magnetic resonance arthrography

ROM Range of motion

MRI Magnetic resonance imaging

PT Physical therapy

DVT Deep venous thrombosis

\section{Introduction}

In 1957, Peterson reported the first tear to the acetabular labrum when two cases of labral tears associated with irreducible posterior hip dislocation were described $[1,2]$. In 1977, Altenberg documented the first report of nontraumatic tearing of the acetabular labrum [2, 3]. Suzuki described the acetabular labrum tear arthroscopically for the first time in 1986 [2, 4].

Although previously thought to be a relatively uncommon injury, acetabular labral tears are becoming diagnosed with increasing frequency because of improvements in MRI and arthroscopic techniques [5]. The prevalence of labral tears in patients with hip or groin pain has been reported to be $22-55 \%$ [6-9].

Besides the symptomatic complaints due to labral tears, the importance of the pathology is its association with degenerative changes. McCarthy et al. found that $73 \%$ of patients with fraying or tearing of the acetabular labrum had chondral damage and that this chondral damage was more severe in patients with labral lesions. They also found that in $94 \%$ of these patients, the articular damage occurred in the same zone of the acetabulum as the labral lesions. They suggested that the relative risk of significant chondral erosion approximately doubles in the presence of a labral lesion. An isolated labral tear was found more often in younger patients, whereas a labral tear in conjunction with 
chondral lesions was found more often in older patients, indicating that a labral tear may precede and possibly lead to articular changes [6]. Leunig demonstrated that joint degeneration is more commonly found in the periphery, as one would expect if the mechanism of joint wear occurs along the weight-bearing surface [10].

The differential diagnosis of labral tears should include the following diagnoses: contusion, strain, athletic pubalgia, osteitis pubis, inflammatory arthritis, osteoarthritis (OA), septic arthritis, piriformis syndrome, snapping hip syndrome, bursitis (either trochanteric, ischiogluteal, or iliopsoas), femoral head avascular necrosis, fracture, dislocation, tumor, hernia (inguinal or femoral), slipped femoral capital epiphysis, Legg-Calve-Perthes disease, or referred pain from the lumbosaral and sacroiliac areas [2].

\section{Anatomy}

The hip joint is a ball-and-socket joint enveloped in dense capsular tissue [11]. The Y-shaped triradiate cartilage acetabulum covers $170^{\circ}$ of the femoral head.[11, 12]. The acetabular labrum is a fibrocartilaginous structure that outlines the acetabular socket [11] (Fig. 1). It is a continuous, usually triangular structure that attaches to the boney rim of the acetabulum and is completed at the inferior portion by the transverse acetabular ligament over the acetabular notch [7, 13-15]. Other variants of the normal triangular shape, including round, irregular, and flattened, have been noted in people without hip pain [7, 16-21]. The incidence of triangular labra decreases with increasing age, whereas the incidence of rounded and irregular margins increases with age $[17,20,21]$. The labrum attaches directly to the nonarticular side of the thin bony rim of the acetabulum and on the articular side, and indirectly through a zone of calcified cartilage and by merging with the acetabular articular hyaline cartilage through a transition zone of 1$2 \mathrm{~mm}[7,15]$. The thickness of the labrum may slightly vary, but it is from 2 to $3 \mathrm{~mm}$ thick [11]. The labrum is wider and thinner in the anterior region and thicker in the posterior region [7, 13, 15, 22-25]. The posterior labrum has a sulcus that can be mistaken for pathology, which will be further described in the evaluation section [11].

The anterior and superior aspects of the labrum are thought to be the most innervated portions, consisting of free nerve endings and sensory nerve end organs. These structures produce pain, pressure, and deep sensation [13, 26]. Most of the labrum is composed of thick, type I collagen fiber bundles principally arranged parallel to the acetabular rim, with some fibers scattered throughout this layer running obliquely to the predominant fiber orientation [27]. The vascular supply is provided by the obturator, superior gluteal, and inferior gluteal arteries [6, 7, 13]. The

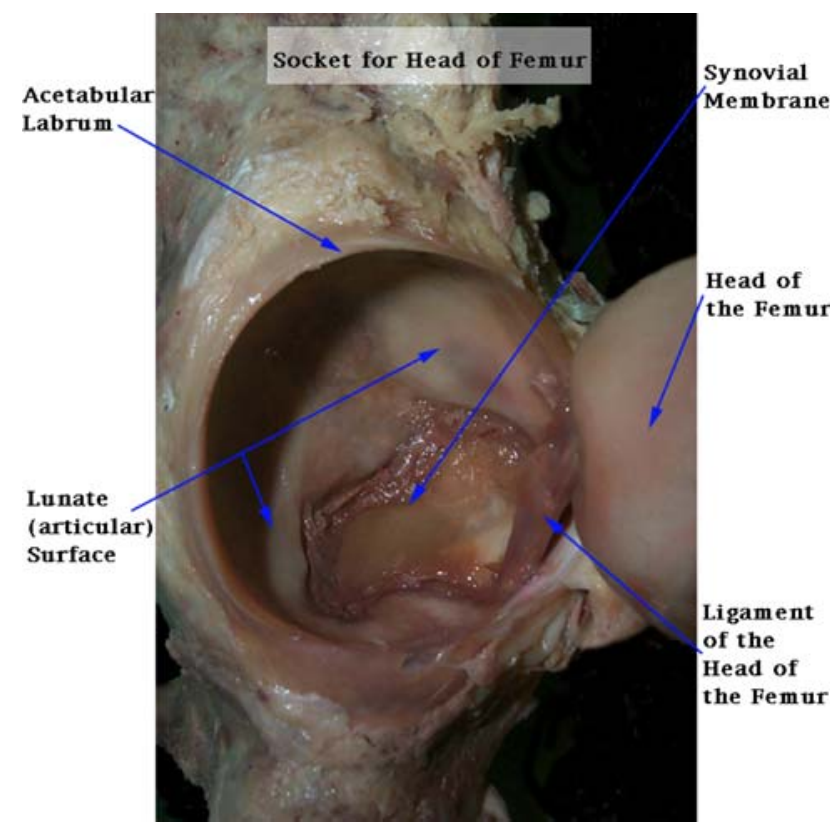

Fig. 1 Photograph demonstrating anatomy of labrum with respect to hip joint. Courtesy of Ithaca College Department of Physical Therapy website (http://www.ithaca.edu/faculty/lahr/LE2000/hip\%20 pics/8acetabularlig.jpg)

blood supply is believed to be mostly peripheral, with the outer one-third of the acetabular base of the acetabular labrum being vascular, while the remaining majority is avascular $[6,7,13-15,22,28,29]$. This is somewhat controversial as McCarthy and colleagues found no areas of relative hypovascularity to the labrum $[6,13]$.

The labrum functions as a sensitive shock absorber, joint lubricator, and pressure distributor [30-34]. The labrum resists lateral and vertical motion of the femoral head within the acetabulum $[11,32,33,35]$. The labrum aids in stability against femoral head translation by deepening the joint. Some studies show that it deepens the acetabulum by $21 \%$. In addition, the labrum increases the surface area of the acetabulum by $28 \%$, which helps distribute load and therefore decrease contact stress on articular surfaces [7, 13, 36]. The labrum also provides a seal for the joint that helps to maintain the synovial fluid and fluid pressure, slowing the consolidation of the articular cartilage, resulting in lower stresses and strains across the hip joint. The intact labrum helps to keep synovial fluid within the articular cartilage, allowing some of the load to be borne by fluid pressurization and preventing direct contact between the femoral head and the acetabular articular cartilage, therefore taking load off these two structures $[5,7,13,32$, 37]. Without the labrum, the articular cartilage must withstand significantly increased pressure, and a compromise of this system could lead to early joint deterioration. A study testing a labrum-free model of the hip showed that, without the labrum, contact stress may increase by as much 
as $92 \%[13,30]$. A tear in the labrum would also likely destabilize the hip joint $[7,14,25,38-40]$. This explains why there is an association between acetabular labral tears and early onset OA [3, 5-7, 15, 30, 32, 33, 41-44].

Labral tears can be classified by their location $[2,5,15$, 45], morphology [2, 5, 11, 15, 46], or etiology [2, 45]. With respect to location, tears are classified as anterior, posterior, or superior/lateral [2,45]. Labral tears can be classified morphologically as: radial flap, radial fibrillated, longitudinal peripheral, and unstable $[11,46]$. Radial flap tears and radial fibrillated tears involve the free margins of the labrum and are the most commonly encountered. Longitudinal peripheral tears of various lengths are seen at the acetabulum-labrum junction, whereas unstable tears follow no real pattern but cause mechanical symptoms [2, 46]. Classification by etiology will be discussed in the next section.

Labral tears have also been classified based on histological analysis of cadaveric specimens. A type 1 labral tear consists of a detachment of the labrum from the articular cartilage surface and occurs at the transition zone between the fibrocartilaginous labrum and the articular hyaline cartilage. This type of tear is perpendicular to the articular surface and, in some cases, extends down to the subchondral bone. A type 2 labral tear consists of one or more cleavage planes of variable depth within the substance of the labrum and extends perpendicular to the surface of the labrum $[2,5,15,46]$.

Across studies, tears were reported in all the regions of the labrum, and occasionally tears occurred in multiple regions in the same hip [7]. Most tears reported in the United States occurred in the anterior portion of the labrum [4-7, 13, 30, 41, 47-51]; however, in Japan the majority of tears occur in the posterior aspect of the labrum, likely due to the frequent practice in Japan of squatting or sitting on the ground or floor $[4,5,7,13,48,49,52]$. Mintz et al. reported $94 \%$ of the labral tears in their series were anterior at surgery [53]. A study by McCarthy et al., arthroscopically evaluating 261 labral tears, found $86 \%$ were located in the anterior quadrant [6]. The most common of all the lesions to occur in the anterior labrum is what McCarthy et al. term the watershed lesion; this is the typical appearance seen after minor trauma in which there is an anterior labral tear present concurrently with anterior acetabular chondral injury [45]. Posterior tears in the Western world occur mainly with discrete episodes of trauma, when a load impacts the femur, driving the femoral head posterior, transferring shear and compressive forces to the posterior labrum [5]. The location of the tear has not proven to have an effect on patient outcome [5, 41, 42].

Different reasons for the prevalence of anterior labral tears have been suggested. One possible explanation is that the anterior region of the labrum has a relatively poor vascular supply compared with the other regions and therefore is more vulnerable to wear and degeneration without the ability for repair $[6,7]$. Another possible explanation for the prevalence of anterior labral tears is that the tissue in the anterior region is mechanically weaker than the tissue in other regions of the labrum $[6,7,15]$. The third and most likely reason for the prevalence of anterior labral tears is that this region is subjected to higher forces or greater stresses than other regions of the labrum. Because of the anterior orientation of both the acetabulum and the femoral head, the femoral head has the least bony constraint anteriorly and relies instead on the labrum, joint capsule, and ligaments for stability. Despite its decreased stability, this area undergoes significant forces during daily activities [7]. The higher force hypothesis may explain why in other cultures posterior tears are more common, where instead of placing greater stress on the anterior area, they place greater stress on the posterior area during their daily living.

Whether or not labral tears have the potential for healing is controversial. With the minimal penetration of vessels into the labrum, some authors have concluded that no area of the labrum has the potential for repair $[6,7,49]$. However, Seldes et al. noted that neovascularization had occurred within the labral tear and substance of the labrum adjacent to the attachment of the labrum to the bone in all the 12 freshly frozen cadaver hips with labral tears that were studied, [7, 15] indicating that the labrum may have some potential for repair, despite no clinical studies to date indicating that labral tears do heal. In contrast, Ikeda et al. found that in one subject who had a labral tear and who had a repeat arthroscopy several months after the initial diagnosis, no healing of the torn tissue had occurred despite the subject's ability to return to sporting activities without a recurrence of pain $[7,49]$.

\section{Etiology}

Historically, labral tears were associated with slipped capital epiphyses, [13, 54] Legg-Calve-Perthes disease, major structural abnormalities of the hip, or high-velocity trauma, such as motor vehicle accidents or falls [13, 55]. It is now proposed that there are at least five etiologies of labral tears-trauma, FAI, capsular laxity/hip hypermobility, dysplasia, and degeneration [56, 57].

Although unusual, isolated traumatic tears of the labrum do occur. These are often a result of significant trauma to the hip joint during contact sports or trauma resulting in either subluxation or dislocation of the femoral head. These traumatic labral tears are often associated with chondral injuries to the femoral head and/or acetabular rim injury [56]. Damage to the acetabular labrum has been reported as 
a cause of irreducible dislocation $[1,15,58]$ or recurrent dislocation $[15,59,60]$ after traumatic dislocation of the hip. Posterior hip dislocations produce posterior labrum tears [15].

Morphologic alterations of the femur or acetabulum can lead to FAI [31, 61], and FAI leads to limited hip range of motion (ROM) and articular cartilage damage [31, 39, 61, 62]. Cam-type FAI is caused by an abnormal femoral headneck junction, which leads to impingement between the abnormal femur and a normal acetabular rim through a peripherally increasing radius entering the acetabulum throughout the ROM of the hip, especially flexion and internal rotation [21, 31, 63, 64]. Pincer-type FAI is the result of abutment of the femoral head-neck junction on the acetabular rim due to acetabular overcoverage causing pinching of the labrum between the femur and acetabulum $[21,31]$. Most cases of FAI reveal combined femoral and acetabular abnormalities. Cam and pincer lesions result in different patterns of articular cartilage damage [31, 62]. As reported from open hip dislocation studies, cam FAI causes damage to the anterosuperior acetabular cartilage with separation between the labrum and cartilage. During flexion, the cartilage is sheared off the bone by the nonspherical femoral head, and the labrum remains initially untouched. In pincer FAI, the cartilage damage is either localized or circumferential and peripheral. During movement, the labrum is crushed between the acetabular rim and the femoral neck, causing degeneration and bony apposition of the adjacent rim [31]. The tip of the labrum (the part farthest from the acetabular bone) remains intact in most cases [31, 65].

Capsular laxity or hypermobility of the hip can result in injury to the labrum. Underlying collagen disorders or hormonal influences on capsular tissue may predispose patients to labral injury resulting from capsular laxity. Repetitive rotational sporting activities, such as golf, place increased stress on the capsular tissue, resulting in attenuation of the iliofemoral ligament. This ultimately leads to rotational instability of the hip, which results in increased pressure on the anterior superior labrum as the head rides anterior in the joint $[2,49,56,66]$.

Patients with labral pathology due to hip dysplasia, have tears that are most frequently anterior, bur can be posterior or diffuse. The labrum tends to be hypertrophic in the anterior portion causing infringement upon the anterior acetabulum. Hypertrophy and tearing most likely cause impingement of the labrum between the acetabulum and femoral head, accounting for the mechanical symptoms frequently seen in this population, including clicking and locking sensations of the hip joint, as well as pain [45]. Dysplastic bony abnormalities include a shallow acetabulum, femoral or acetabular anteversion, a reduction in acetabular or femoral anteversion, acetabular retroversion, and a decreased head offset or perpendicular distance from the center of the femoral head to the axis of the femoral shaft [7, 61, 63, 67-72]. Any combination of these abnormalities leads to a change in the position of the femur within the acetabulum, whichoften results in joint incongruity or decreased joint surface area, most commonly anteriorly, and increased stresses on the acetabulum and the labrum [7, 50, 54, 73-75]. The increased stresses may lead to fatigue fracture of the acetabular rim and separation of a rim fragment or detachment of the overstressed labrum from the acetabulum $[7,50]$. Labral tears have been well documented in people with hip dysplasia $[7,39,50,73$, 76]. In a study of patients with mild-to-moderate hip dysplasia and hip pain, McCarthy and Lee found that $72 \%$ of the 170 hips studied had labral tears, and $93 \%$ of these tears were in the anterior region of the labrum [76]. In patients who have developmental dysplasia of the hip (DDH), labral pathology should be considered when a patient's pain is out of proportion to radiographic changes [21]. Also, before performing osteotomy in these individuals, it may be worthwhile to have them undergo MRA to rule out labral pathology since failure to address the associated labral pathology may lead to a poor outcome after osteotomy [21]. Labral pathology should be considered in patients who have undergone a technically successful osteotomy but continue to have pain [21].

Although the cause of labral degeneration for developmentally dysplastic hips has been attributed to chronic shear stresses $[31,50]$, Until recently there has been no mention of the mechanisms underlying labral failure in nondysplastic hips [31, 61, 77]. In this latter group of patients, structural abnormalities about the hip such as a decreased anterior head-neck offset of the proximal femur and/or local or general acetabular overcoverage may result in FAI and subsequent soft tissue failure. McCarthy et al. proposed the following sequence of events: traction or impingement (such as that from FAI or DDH) leads to excessive loading of the labrum at the extremes of joint motion, which leads to fraying along the articular margin of the labrum, which leads to tearing of the articular margin of the labrum, which leads to delamination of the articular cartilage, which produces a cartilage flap adjacent to the labral lesion and eventually more global labral and chondral pathology [6]. Peelle and colleagues studied the radiographs of 78 patients treated arthroscopically for labral tears. Forty-nine percent of patients with symptomatic labral tears were found to have at least one radiographic abnormality: $17 \%$ occurred at the acetabulum, $14 \%$ at the femur, and $18 \%$ at both anatomic sites. The abnormal articular loading and increased stresses caused by hip dysplasia and FAI results in progressive labral and chondral injury, and can lead to the development of acetabular labral tears, articular cartilage delamination, and eventual secondary OA $[13,31]$. 
Degeneration is the final described etiology of labral tears. It has been suggested that these tears may represent the natural history of the aged joint, as labral abnormalities have been found in patients without hip pain with the incidence increasing with age [7, 13, 16, 17, 19, 20]. In cadaver studies, labral tears and abnormalities were found in $93-96 \%$ of hips [6, 7, 13, 15, 38].

Labral tears in the athletic population can occur from an isolated traumatic event or from repetitive trauma [11, 78]. Hip dislocations are susceptible to labral tears [11], and acetabular fractures that occurred from football injuries have also been associated with labral tears [11, 78, 79]. However, up to $74.1 \%$, are not associated with any known specific event or cause, and these are generally insidious in onset, with the underlying inciting event thought to be repetitive microtrauma $[6,7,11,13,35,47,54,79,80]$. Athletic activities that involve repetitive pivoting motions on a loaded femur have been associated with damage to the acetabular labrum [13, 81, 82]. Specific sporting activities, such as soccer, hockey, golf, and ballet, have been linked to labral abnormalities, because they require frequent external rotation $[6,7,11,13,38,54,80,83]$. Some tears also have been attributed to running and sprinting [7, 42, 49]. The end-range motion in positions of hyperabduction, hyperextension, hyperflexion, and external rotation is thought to contribute to the higher incidence of labral tears seen in this population of active individuals [2, 6, 13, 38, 54]. It is thought that the labrum takes on a weight-bearing role at the extreme of motion with excessive forces leading to tearing [2].

The most common associated lesions with labral tears in athletes are chondral injuries, which are usually adjacent to the labral pathology [11, 78-80]. These include chondromalacia, thinning of the cartilage, delamination of the cartilage, chondral flap tears, and full-thickness chondral injury with exposed bone [11]. Lateral impaction injuries seen with football injuries have been reported [11, 84]. Ligamentum teres in conjunction with labral tears has been reported [11, 79]. This ligament tightens in external rotation, and may have a secondary stabilizer role with labral deficiency [85]. Displaced ligamentum teres tears can cause impingement with hip flexion [11]. Synovitis and potential loose bodies can occur with labral tears in athletes [11]. It must also not be forgotten, that underlying structural, such as FAI and developmental abnormalities, can also predispose athletes to labral pathology. Labral tears in athletes can lead to disabling hip pain and affect their athletic performance, but return to sport is favorable in athletes if the tears are properly treated with arthroscopic intervention $[11,79,86]$. The earliest return to sport was seen with the golfers (average 6 weeks), followed by hockey players and skaters. Baseball and soccer players averaged 12 weeks [79]. Of course, any additional surgical techniques needed to address bony abnormalities may potentially prolong return to sport [11].

The search for biomechanical predisposing factors may be of benefit in cases of labral tears. Janda has described a predictable pattern of muscular imbalance in the pelvis, known as the lower crossed syndrome. Tightness of the hip flexors and lumbar erector spinae and weak, inhibited gluteal and abdominal muscles characterize lower crossed syndrome. The resultant imbalance leads to anterior pelvic tilt, increased hip flexion, and a hyperlordosis of the lumbar spine. Hip flexion contracture might lead to increased weight bearing on the anterior acetabulum and labrum predisposing to tearing. Many patients presenting in the primary setting with low back pain due to lower crossed syndrome can be rehabilitated to correct these aberrant pelvic mechanics. If the patient is participating in high-risk sports, they may be in a position to distribute forces more evenly around the labrum and acetabulum, reducing the risk of tearing [87].

\section{Clinical presentation}

Labral tears are a frequent cause of anterior hip and groin pain [13]. Patients with labral tears commonly go undiagnosed during an extended period of time and patients are often seen by multiple health care providers before obtaining a definitive diagnosis [13, 35, 88]. Studies have shown that there is on average greater than 2 years before diagnosis is achieved [7, 8, 41, 42, 89, 90]. Studies have shown that $22 \%$ of athletes with groin pain $[7,9,27]$ and $55 \%$ of patients with mechanical hip pain of unknown etiology $[6,7]$ were found to have a labral tear upon further evaluation.

Labral tears may be diagnosed in both sexes and throughout all ages. Most studies report that symptomatic labral tears occur more frequently in women than in men $[6,7,13,35,41,42,47-49,73]$. This may partly be due to the increased incidence of hip dysplasia in women, especially in the age range of $15-41$ years $[4,6,7,13,35,41$, 42, 47-49, 73, 91]. However, hip dysplasia alone cannot account for the sex difference because many patients with labral tears do not have dysplasia [7]. The reported age range of people with hip pain and a labral tear is from 8 to 75 years [3, 6-8, 41, 42, 44, 47-49, 54, 73, 83, 90, 92, 93].

More than $90 \%$ of patients diagnosed with acetabular labral tears complain of anterior hip or groin pain $[6,7,13$, 35, 38, 42, 44, 48, 50, 51, 83, 89]. Pain is less often reported in the lateral region or deep in the posterior buttocks [7, 44, 48, 54] and pain may radiate to the knee [2]. Burnett and colleagues studied 66 patients found to have labral tears by arthroscopy and reported $92 \%$ had predominant localized groin pain, $52 \%$ had associated anterior 
thigh pain, 59\% described lateral hip pain, and $38 \%$ reported associated buttock pain, while no patient presented with isolated buttock pain [13, 35]. Unique in women is the possible concomitant pelvic-floor pain that may occur [13]. Data suggest that anterior hip or groin pain is more consistent with an anterior labral tear, whereas buttock pain is more consistent with a posterior labral tear [48].

Patients with a labral tear also report a variety of mechanical symptoms, including clicking, locking or catching, or giving way $[3,7,9,13,41,44,47,54,73,75]$. Of these symptoms, clicking appears to be the most consistent clinical symptom [7, 9]. In addition, a labral tear can also contribute to hip instability [94].

The onset of symptoms was described as insidious in $61 \%$ of patients. Many patients with labral tears describe a constant dull pain with intermittent episodes of sharp pain that worsens with activity. Walking, pivoting, prolonged sitting, and impact activities, such as running, often aggravate symptoms. Seventy-one percent of patients describe night pain [13]. Functional limitations include, limping (89\%), needing a banister to climb stairs (67\%), limitation of walking distance (46\%), and sitting limited to $30 \min (25 \%)$ [35].

The most consistent physical exam finding in patients with acetabular labral tears is a positive anterior hipimpingement test $[13,35,92]$. This is performed with the patient supine with the hip and knee at $90^{\circ}$ of flexion. The hip is internally rotated while an adduction force is applied. A positive test results in pain provocation in the anterolateral hip or groin. Another test used is the posterior hip impingement test, in which the patient lies prone with hip and knee extended and the examiner passively extends, adducts, and externally rotates hip. A positive test reproduces anterior hip or posterior pelvic pain [13]. These tests are also used for diagnosis of FAI [31, 95]. Other, less specific tests used include the Patrick/Faber test, Resisted straight leg raise test/Stitchield test, Log-roll test, and the Apprehension test $[7,13,31]$. However, physical exam findings remain inconsistent, likely because of the variable locations of labral tears.

Several researchers have reported slight hip ROM limitations. The most commonly reported ROM limitation was in rotation, but hip flexion, adduction, and abduction ROM limitations also have been reported $[3,7,42,44$, $48,83,96,97]$.

\section{Evaluation}

Diagnostic imaging usually begins with a radiographic evaluation with special attention to subtle structural abnormalities of the hip and pelvis. Screening radiographs help detect obvious sources of disease, such as advanced arthritis, tumor, DDH, or FAI. A complete evaluation includes an anteroposterior view of the pelvis, a cross-table lateral view with or without a frog lateral view and a false profile view. These projections allow for specific measurements of the acetabulum and femoral head to improve recognition of subtle DDH or FAI [13, 98, 99]. Standard radiographs are typically normal [7, 42, 49]; however, radiographs of some patients may show degenerative changes [3, 7, 93], dysplasia [7, 48, 73, 93], evidence of prior surgeries [7, 42], or subtle bony abnormalities, including coxa valga, a small head-neck offset, or acetabular retroversion $[7,77]$.

Computed tomography scans are unable to reliably detect labral tears [7, 47, 50], and MRI alone is also inadequate for visualizing the acetabular labrum. Standard MRI produces both false-positive results and an underestimation of labral pathology and has only $30 \%$ sensitivity and $36 \%$ accuracy $[7,100]$. Bone scintigraphy recently was proposed as a way of detecting a labral tear, as scans in patients with tears showed characteristic patterns of increased uptake in the superior aspect of the acetabulum: however, the full diagnostic value of this has yet to be determined [7, 101].

MRA produces better results, as the intraarticular or systemic infusion of gadolinium is required to obtain the detail necessary to study the labrum $[13,102]$. The principle of the procedure relies upon capsular distension, thereby outlining the labrum with contrast and filling any tears that may be present [45]. A study by Czerny et al. showed the sensitivity and accuracy for nondistended joints were $30 \%$ and $36 \%$, respectively, while the sensitivity and accuracy increased to $90 \%$ and $91 \%$, respectively, after joint distention, proving the importance of capsular distension [100]. An MRA is also helpful to rule out other abnormalities within the differential, which include but are not limited to stress fractures, neoplasm, avascular necrosis, osteitis pubis, synovitis, ligamentum teres rupture, and other extraarticular soft tissue abnormalities, such as sports hernias and tendon avulsions. Criteria for tears on an MRA include contrast extending into the labrum or acetabular/ labral interface, blunted appearance, and displacement/ detachment from underlying bone [11, 103]. The labrum is typically of diffused low signal intensity on all imaging sequences: however, a wide spectrum of intermediate intrasubstance signal has been reported in asymptomatic labra [21]. Focal intermediate to slightly high signal intensity may be seen at the labral base [19, 21, 23, 104], and the incidence of intrasubstance signal increases with increasing age $[17,20,21]$ and is more common in men than women [17, 21]. This intermediate signal is most commonly located within the superior and anterior labrum but may be identified at any point within the joint [21]. 
MRA has its limitations in regard to sensitivity for diagnosis of acetabular labral and articular cartilage abnormalities. Studies have compared MRA with surgical findings and have shown a range of sensitivity from $60 \%$ to $100 \%[13,23,24,100,102,105-109]$ and that of specificity from $44 \%$ to $100 \%[13,28,105,107,110]$ for acetabular labral pathology as compared to direct surgical visualization. These studies demonstrate that a negative scan does not fully rule out a labral tear and that hip arthroscopy remains the gold standard [7]. A potential pitfall in diagnosing labral tears is false positives, such as those which may occur when there is the normal anatomic variant of recesses or sulci. Sublabral recesses may occur anteriorly [107] and posteriorly, but since hip labral pathology is much more frequently anterior than posterior, the anterior recesses are more of a concern for false positives. A study by Studler et al. showed the presence of a normal sublabral recess in the anterior aspect of the acetabulum in $18 \%$ (10 out of 57) of symptomatic patients undergoing hip surgery [107].To differentiate between the two, the authors proposed that since recesses do not extend through the full thickness of the labral base, as many tears do, if there is contrast material interposed at the base in the anterosuperior portion of the labrum, then it should be considered as a labral tear [107]. There are several sulci that need to be identified when evaluating MRA to prevent false positives. First of these are the perilabral sulci/recess, which are located at the labrocapsular junction on the capsular surface of the labrum. They are normal, although loss of the sulcus can be an indicator of labral disease [100]. Next is the sulcus created by the junction of the transverse ligament and the labrum, also a normal finding, known as the labroligamentous sulcus [21]. Another sulcus is located at the posteroinferior aspect of the joint,which has recently been described as a normal variant [111].

MRA may also be less effective in identifying posterior and lateral tears. Whereas, McCarthy et al. showed a $74 \%$ sensitivity for detecting anterior tears, the sensitivity for the detection of posterior tears was $20 \%$ and for lateral tears was $11 \%$ [45].

Diagnostic-image-guided intraarticular hip injections can also be helpful in the diagnosis of labral tears. Prior studies have shown that fluoroscopically guided diagnostic hip injections have $88 \%$ sensitivity and $100 \%$ specificity for localizing groin pain to an intraarticular location [13, 112]. Other studies have shown $90 \%$ accuracy of diagnostic hip injections to detect the presence of intraarticular abnormality when compared to hip arthroscopy [13].

Arthroscopy, which is considered the gold standard, can be a diagnostic and therapeutic medium. However, when used for diagnosis, it is reserved for those patients with an intra-articular source of pain without a clear diagnosis after careful history, physical exam, and radiographic studies [113].

\section{Treatment}

Typically, a trial of conservative management, including relative rest, anti-inflammatory medications, and pain medications as necessary, combined with a focused PT protocol for 10-12 weeks is recommended initially. The patient's pain may be reduced during this period of limited activity;however, the pain often recurs when the patient returns to his or her normal activities [7]. Occasionally, it is necessary to restrict weight bearing in patients with acute or traumatic onset of symptoms. A fluoroscopically guided intraarticular injection with or without steroid can also be used to quiet an acute flare. The decision to add a longacting steroid to the injectate should be based on the degree of associated degenerative changes seen on radiographic evaluation. In a young patient with no degenerative changes, intraarticular steroids may damage chondral surfaces and are not recommended [13].

Lewis and Sahrmann recently described a PT protocol for acetabular labral tears with the goal of optimizing the alignment of the hip joint and the precision of joint motion by reducing anteriorly directed forces on the hip and addressing abnormal patterns of recruitment of muscles that control the hip [7]. Limiting pivoting motions and other movement patterns that increase forces across the labrum is of utmost importance because the acetabulum rotates on a loaded femur. Much of the focus is on strengthening muscles found to be inhibited, analyzing gait, and retraining as indicated. Assessing foot motion, especially through the subtalar joint, and correcting stiffness or adding support to the medial arch through taping or orthotics are crucial in making corrections to gait patterns. The strengthening pattern is progressed over time to maintain long-term success in treatment. This can be done through increasing the lever arm length of a particular exercise, adding weight-bearing exercises, and enhancing proprioception and balance through the use of uneven surfaces, balance boards, or force challenges. Ultimately, some of the exercises should resemble the functional activities the patient is trying to return to or accomplish [7,13]. The use of PT is somewhat controversial, and Hickman and Peters concluded that PT is of no significant benefit and is not recommended for patients with a labral tear [75].

With the train of thought that the labrum is a relatively avascular structure, it is thought that restricted ROM causes lower rates of imbibition and compromised nutrition, therefore manual procedures aimed at restoring ROM will also increase the rate of nutrient flow and may promote labral healing [2]. In cases of entrapped or folded labral portions, manual procedures, including hip joint tractional maneuvers, may be of benefit [2].

When conservative measures do not control the patient's symptoms or when functional limitations remain unsatisfactory, a surgical referral is appropriate. Previously, it was 
believed that the labrum had little functional importance and that the appropriate treatment for symptomatic labral tears was excision [5, 42, 47, 114]. The philosophy has changed because of the evidence supporting the acetabular labrum's role in preventing premature arthritis, enhancing stability of the hip joint, and participation in nociception and proprioception [56]. In regard to current treatment, the literature to date has focused on arthroscopic debridement of labral tears and surgical repair of associated structural problems [13, 35, 38, 42, 54, 89, 115, 116]. In an effort to prevent subsequent joint degeneration after labral injury, open [5, 117, 118] and arthroscopic [5, 41, 119, 120] approaches have been employed. Repair is particularly important for peripheral labral tears, which have the blood supply to heal $[14,29,56]$. The goal of arthroscopic treatment of a torn labrum is to relieve pain by eliminating the unstable flap tear that causes hip discomfort [94].

Arthroscopic technique was described well by Bharam [11]. The procedure can be performed by either a supine, lateral, or modified supine approach. General or spinal anesthesia is given for optimal muscle relaxation in order to minimize the amount of traction needed for distraction [56]. An oversized peroneal padded post is used to minimize pudendal nerve injury, and the feet are also wellpadded. Portal placement consists of an anterior, an anterolateral, and distal lateral ports [56]. Additional portals can be made posteriorly with care to avoid the sciatic nerve. Distal accessory portals can be used for accessing the peripheral compartment to perform femoral neck osteoplasty or trochanteric bursectomy [25, 121]. Distraction of the femoral head from the acetabulum must be performed to fully visualize the articular surfaces [56]. Access of the hip joint can be done under fluoroscopic guidance, allowing the anterior portal to be placed under direct visualization and avoiding iatrogenic chondral and labral injury [122, 123]. A diagnostic arthroscopic examination of the central compartment can be done to locate possible cartilage lesions on both the acetabular and femoral side, potential ligamentum teres tears, and loose bodies in the fovea, and to assess capsular abnormalities, such as laxity. The labrum and labrocapsular junction are closely evaluated for structural integrity and probed to rule out detachment to the acetabular rim and acetabular rim lesions. The peripheral compartment is evaluated to assess cam-type impingement and abnormalities in the head and neck junction and potential loose bodies.

In managing labral tears, the surgeon focuses on preserving healthy labral tissue in order to maintain its role as a secondary joint stabilizer and to minimize potential arthrosis [124]. Fraying from labral tears is debrided with motorized shavers and radiofrequency probes. Intrasubstance labral tears and detachment of labral tears off the acetabular rim are repaired by placing an absorbable suture through the defect and retrieving the suture through the capsule. Adjacent cartilage lesions should also be debrided and stabilized with the use of shavers and radiofrequency probes to minimize further propagation. Chondral lesions can be managed with microfracture techniques to stimulate fibrocartilage.

Arthroscopy also allows visualization of related intraarticular structures, such as the articular cartilage and ligamentum teres. McCarthy and colleagues found $63 \%$ of hips scoped for labral tears were found to have articular cartilage abnormalities. In $80 \%$ of these patients, labral and articular lesions were found in the same zone of the acetabulum as the labral tear, with most lesions in the anterior quadrant of the acetabulum $[13,38]$. In patients with significant associated structural abnormalities, arthroscopic debridement alone is commonly inadequate. Depending on the underlying type of structural abnormality, other jointpreserving procedures may be indicated. Dorrell and Catterall [73] reported on 11 patients who had acetabular dysplasia and an associated labral tear and who received surgical intervention. They found that the best surgical outcomes were achieved when the torn labrum was excised and a procedure to improve the containment of the femoral head within the acetabulum was performed.

Ligamentum teres tears, which can cause impingement and be a source of disabling pain, can be debrided to a stable remnant. For capsular laxity, focal thermal capsulorrhaphy, and capsular plication at the level of the iliofemoral ligament are performed to reduce capsular redundancy [78, 94]. Localized capsular elongation adjacent to the labral tear can be managed with capsulorrhaphy [40]. Loose bodies, most commonly found in the fovea region, are removed with arthroscopic graspers and shavers [125]. Patients with FAI may benefit from a femoral and/or acetabular osteoplasty procedure with the use of motorized burrs and shavers [5, $13,31,116,121]$ and possibly rim trimming if they have a moderate-to-severe pincer impingement [31]. Likewise, patients with associated DDH may benefit most from acetabular reorientation for correction of the dysplasia $[13,67$, 126]. Painful snapping iliospoas tendonitis can be relieved through partial releases performed arthroscopically. Endoscopic releases can be performed with lengthening of the iliotibial band and bursectomy for iliotibial band syndrome and trochanteric bursitis [127], for which athletes, and particularly runners, are at high risk. Removal of calcific tendonitis of the gluteus medius tendon has been reported with endoscopic techniques [86].

The overall reported complication rate with arthroscopy of the hip ranges from $1.4 \%$ to $25 \%$ [2, 7, 8, 41, 42, 90, 93, 119, 128-132]. Complications after arthroscopy include deep venous thrombosis (DVT), articular damage, and neurovascular injury [7, 31]. The particular nerves at risk include the superior gluteal neurovascular bundle, lateral femoral cutaneous nerve, and the femoral neurovascular 
bundle due to portal placement, and the sciatic and pudendal nerves due to traction [31, 41, 90, 128, 130-132]. These nerve palsies are typically transient and resolve in a period of $2 \mathrm{~h}$ to 3 weeks $[130,131]$.

Studies report varied results after arthroscopic debridement. Burnett and colleagues reported $89 \%$ of patients with continued "improved" status at an average of 16.5 months after arthroscopic debridement of a labral tear [13, 35]. Similar results are seen across the literature, including in multiple case studies $[3,13,35,38,41,42,44,48,49,54$, 73, 115]. However, other studies show less conclusive results. In a study by Farjo et al., 28 patients who underwent arthroscopic debridement of a labral tear were questioned with regard to their pain, mechanical symptoms, general activity level, activities of daily living, work ability, and ability to return to sporting activities; Only 13 patients (46\%) reported being "better" or "much better" in all of these categories when monitored for at least 1 year [41]. Santori and Villar included 58 patients for a mean follow-up of 3.5 years, who underwent resection of a labral tear, and when these patients where questioned with regard to whether or not they were satisfied with the results of their surgery, $39(67.3 \%)$ reported being "pleased" with the results of the surgery, whereas $32.7 \%$ were not pleased [47]. Success rates are lower with worsening degrees of labral tear and secondary OA changes. McCarthy and colleagues reported that out of patients with stage 3 labral tears (diffuse tears that involve more that one anatomic region and are associated with more pronounced degenerative changes) $40 \%$ had good-to-excellent results compared with $91 \%$ good-to-excellent results in patients with stage 1 labral lesions (localized to one anatomic region with mild degenerative changes) [13, 38]. Farjo et al. [41] reported associated arthritic changes as a poor prognostic indicator to arthroscopic repair of labral tears. Only $21 \%$ of patients ( 3 out of 14) with arthritis detectable on radiographs had good results from surgery, compared with $75 \%$ of patients without arthritis. Furthermore, $43 \%$ of patients (6 out of 14) with arthritis went on to undergo total hip arthroplasty, whereas only $14 \%$ of patients ( 2 out of 14 ) without arthritis went on to have the arthroplasty. Byrd and Jones lent support to this, reporting a $31 \%$ improvement in average modified Harris Hip Score following debridement in patients with isolated labral tears versus an $18 \%$ improvement in patients with a labral tear and chondral injury [5,90]. Other studies have shown similar results [13, 89, 90, 93, 115, 116, 133]. Arthroscopic detection of chondromalacia was an even stronger indicator of poor long-term prognosis [41].

Robertson et al. performed a systematic review to determine the rate of patient satisfaction that can be expected following acetabular labral debridement. Literature between January 1980 and September 2005 that included patients with symptomatic acetabular labral tears who failed conservative management, were not claiming workers' compensation, and did not have severe arthritis or severe acetabular dysplasia, and had at least 2 years follow-up, was analyzed. Their conclusions were as follows: at least $67 \%[5,49]$, and as high as $91 \%[5,89]$ of patients will be satisfied with their outcome at 3.5 years, there were good results by a modified Harris Hip Score in patients who are subjectively satisfied with their outcome [5, 105], and a complete resolution of mechanical symptoms was seen in nearly $50 \%$ of patients with this complaint $[5,134]$, with as high as $90 \%$ having some reduction in the frequency of these symptoms [5, 89].

Medical after hip arthroscopy focuses on the prevention of heterotopic ossification, through the use of a strong non-steroid anti-inflammatory agent for 2 weeks postoperatively, and DVT, through the use of mechanical compression devices and pharmacotherapy for 4 weeks. Pharmacotherapy options available for DVT prevention include high-dose aspirin, warfarin, and low-molecular weight heparin injectables [31].

Dirocco et al. have many impairments after arthroscopy; these included inflammation, pain, swelling, decreased joint mobility, altered muscle extensibility, impaired muscle strength, altered proprioception, and decreased muscle endurance. Rehabilitation protocols should be designed to address these impairments [135]. Therefore, the initial period after surgery is focused to decrease pain and effusion, prevent muscle inhibition, promote tissue nutrition and wound healing, maintain proper static joint alignment, increase awareness of joint protection, allow an independent and safe gait with assistive device on all the level surfaces and elevations, and increase sitting tolerance [135]. The course and requirements of postoperative rehabilitation depend on the operative procedures. A simple diagnostic hip arthroscopy with biopsy, limited debridement, or capsular release needs minimal postoperative weight bearing and ROM protection. The patient usually is able to bear weight as tolerated on the involved extremity. Such patients can progress through the same exercises as those designed for a patient before surgery as long as no symptoms are present; this consists of restoring hip ROM and correcting faulty movement and gait patterns while improving muscle strength and endurance, with eventual progression to activity-specific exercises and plyometric training with slow return to work or sporting activity [2]. Active straight leg raising should be avoided, which also includes any type of trunk curl with the hip in flexion (i.e. performing a sit-up). Any exercises requiring hip extension beyond neutral, such as prone hip extension exercises or lunges, in which the hip on the stance side is hyperextended, also should be avoided [7].

More invasive techniques such as osteoplasty, rim trimming with labral repair, or chondral procedures require additional protection. The patient is usually non-weight bearing or toe-touch weight bearing for 6 weeks, followed by weight bearing as tolerated [7]. PT first should restore 
passive motion followed by active motion, with restoration of internal rotation before external rotation [31]. During the initial 6-week period, active and active-assisted exercises in gravity-minimized positions are used to maintain motions of the hip. Stationary cycling (avoiding a recumbent bike) without resistance is a good exercise to provide motion to the hip and maintain endurance of the lowerextremity musculature. In addition, any end-range hip flexion is best performed passively rather than actively and should be performed only in a pain-free range [7]. Endurance strengthening is commenced after motion is maximized and full weightbearing begun. Active hip flexion is limited for 3-4 weeks to reduce the incidence of hip flexor tendonitis [31].

Patients are seen during the 4- to 6-week postoperative mark for clinical as well as radiographic follow-up. Anteroposterior pelvis and cross-table lateral views of the operative hip are obtained to assess for restoration of femoral head-neck concavity and positioning of osteochondral grafting or resurfacing [31]. Return to sport is usually possible in 2-4 months [2].

\section{Conclusion}

The prevalence range of labral tears in patients with hip or groin pain has been reported to be from $22 \%$ to $55 \%$ [6-9]. However, studies have shown that there is on average greater than 2 years before diagnosis $[7,8,41,42,89,90]$ and patients often have to see multiple health care providers to obtain this diagnosis [13, 35, 88]. MRA is now the diagnostic test of choice. When conservative measures fail, surgery is necessary and the philosophy behind this has shifted, now that there is evidence supporting the acetabular labrum's role in preventing premature arthritis [56]. Previously, the was excision [5, 42, 47, 114], now surgeons perform arthroscopic debridement of labral tears to preserve as much healthy labral tissue as possible $[13,35,38,42,54,89,115,116]$.

Future developments, will likely include improved diagnostic media considering the difficulty in diagnosis. Recently, bone scintigraphy was proposed as a way of detecting labral tears: however, the full diagnostic value of this has yet to be determined $[7,101]$.

Open Access This article is distributed under the terms of the Creative Commons Attribution Noncommercial License which permits any noncommercial use, distribution, and reproduction in any medium, provided the original author(s) and source are credited.

\section{References}

1. Dameron TB. Bucket handle tear of acetabular labrum accompanying posterior dislocation of the hip. J Bone Joint Surg. 1959;41A:131-4.
2. Schmerl M, Pollard H, Hoskins W. Labral injuries of the hip: a review of diagnosis and management. J Manipulative Physiol Ther. 2005;28(8):632.

3. Altenberg AR. Acetabulur labrum tears: A cause of hip pain and degenerative arthritis. South Med J. 1977;70:174-5.

4. Suzuki S, Away G, Okada Y, et al. Arthroscopic diagnosis of ruptured acetabular labrum. Acta Orthop Scand. 1986;57:513-5.

5. Robertson WJ, Kadrmas WR, Kelly BT. Arthroscopic management of labral tears in the hip: a systematic review. Clin Orthop Relat Res. 2007;455:88-92.

6. McCarthy JC, Noble PC, Schuck MR, et al. The Otto E Aufranc Award the role of labral lesions to development of early degenerative hip disease. Clin Orthop. 2001;393:25-37.

7. Lewis CL, Sahrmann SA. Acetabular labral tears. Phys Ther. 2006;86:110-21.

8. McCarthy JC, Busconi B. The role of hip arthroscopy in the diagnosis and treatment of hip disease. Orthopedics. 1995;18: 753-6.

9. Narvani AA, Tsiridis E, Kendall S, Chaudhuri R, Thomas P. A preliminary report on prevalence of acetabular labrum tears in sports patients with groin pain. Knee Surg Sports Traumatol Arthrosc. 2003;11:403-8.

10. Leunig M, Beck M, Woo A, Dora C, Kerboull M, Ganz R. Acetabular rim degeneration: a constant finding in the aged hip. Clin Orthop Relat Res. 2003;413:201-7.

11. Bharam S. Labral tears, extra-articular injuries, and hip arthroscopy in the athlete. Clin Sports Med. 2006;25(2):279-92. ix.

12. Wasielewski RC. The hip. In: The adult hip. Philadelphia: Lippincott-Raven; 1998.

13. Hunt D, Clohisy J, Prather H. Acetabular tears of the hip in women. Phys Med Rehabil Clin N Am. 2007;18(3):497-520.

14. Petersen W, Petersen F, Tillmann B. Structure and vascularization of the acetabular labrum with regard to the pathogenesis and healing of labral lesions. Arch Orthop Trauma Surg. 2003;11:403-8.

15. Seldes RM, Tan V, Hunt J, et al. Anatomy, histologic features, and vascularity of the adult acetabular labrum. Clin Orthop Relat Res. 2001;382:232-40.

16. Abe I, Haranda Y, Oinuma K, et al. Acetabular labrum: abnormal findings at MR imaging in asymptomatic hips. Radiology. 2000;216(2):576-81.

17. Lecouvet FE, Vande Berg BC, Malghem J, Lebon CJ, Moysan $P$, Jamart J, et al. MR imaging of the acetabular labrum: variations in 200 asymptomatic hips. Am J Roentgenol. 1996;167:1025-8.

18. Won YY, Chung IH, Chung NS, Song KH. Morphological study on the acetabular labrum. Yonsei Med J. 200;44:855-62.

19. Cotten A, Boutry N, Demondion X, Paret C, Dewatre F, Liesse A, et al. Acetabular labrum: MRI in asymptomatic volunteers. J Comput Assist Tomogr. 1998;22:1-7.

20. Abe I, Harada Y, Oinuma K, Kamikawa K, Kitahara H, Morita F, et al. Acetabular labrum: abnormal findings at MR imaging in asymptomatic hips. Radiology. 2000;16:576-81.

21. Petersilge C. Imaging of the acetabular labrum. Magn Reson Imaging Clin N Am. 2005;13(4):641-52, vi.

22. Keene GS, Villar RN. Arthroscopic anatomy of the hip: an in vivo study. Arthroscopy. 1994;10(4):392-9.

23. Czerny C, Hofmann S, Urban M, et al. MR arthrography of the adult acetabular capsular-labral complex: correlation with surgery and anatomy. AJR Am J Roetgenol. 1999;173:345-9.

24. Petersilge CA, Haque MA, Petersilge WJ, Lewin JS, Lieberman JM, Buly R. Acetabular labral tears: evaluation with MR arthrography. Radiology. 1996;200(1):231-5.

25. Kelly BT, Williams RJ III, Philippon MJ. Hip arthroscopy: current indications, treatment options, and management issues. Am J Sports Med. 2003;31:1020-37. 
26. Kim YT, Azuma H. The nerve endings of the acetabular labrum. Clin Orthop. 1995;320:176-81.

27. Narvani AA, Tsiridis E, Tai CC, Thomas P. Acetabular labrum and its tears. Br J Sports Med. 2003;37(3):207-11.

28. Keeney JA, Peelle MW, et al. Magnetic resonance arthrography versus arthroscopy in the evaluation of articular hip pathology. Clin Orthop Relat Res. 2004;429:163-9.

29. Kelly BT, Shapiro GS, Digiovanni CW, et al. Vascularity of the hip labrum: a cadaveric investigation. Arthroscopy. 2005;21(1): $3-11$.

30. Ferguson SJ, Bryant JT, Ganz R, et al. The influence of the acetabular labrum on hip joint cartilage consolidation: a poroelastic finite element model. J Biomech. 2000;33(8):953-60.

31. Philippon MJ, Stubbs AJ, Schenker ML, Maxwell RB, Ganz R, Leunig M. Arthroscopic management of FAI: osteoplasty technique and literature review. Am J Sports Med. 2007;35(9):1571-80.

32. Ferguson SJ, Bryant JT, Ganz R, Ito K. The acetabular labrum seal: a poroelastic finite element model. Clin Biomech. 2000; 15:463-8.

33. Ferguson SJ, Bryant JT, Ganz R, Ito K. An in vitro investigation of the acetabular labral seal in hip joint mechanics. J Biomech. 2003;36:171-8.

34. Ferguson SJ, Bryant JT, Ito K. The material properties of the bovine acetabular labrum. J Orthop Res. 2001;19:887-96.

35. Burnett S, Della Rocca G, Prather H, et al. Clinical presentation of patients with tears of the acetabular labrum. J Bone Joint Surg Am. 2006;88(7):1448-57.

36. Tan V, Seldes RM, Katz MA, et al. Contribution of acetabular labrum to articulating surface area and femoral head coverage in adult hip joints: an anatomic study in cadavera. Am J Orthop. 2001;30(11):809-12.

37. Hlavacek M. The influence of the acetabular labrum seal, intact articular superficial zone and synovial fluid thizotropy on squeeze-film lubrication of a spherical synovial joint. J Biomech. 2002;35(10):1325-35.

38. McCarthy J, Nable P, Alusio FV, et al. Anatomy, pathologic features and treatment of acetabular labral tears. Clin Orthop Relat Res. 2003;406:38-47.

39. Leunig M, Podeszwa D, Beck M, Werlen S, Ganz R. Magnetic resonance arthrography of labral disorders in hips with dysplasia and impingement. Clin Orthop Relat Res. 2004;418:74-80.

40. Philippon MJ. The role of arthroscopic thermal capsulorrhaphy in the hip. Clin Sports Med. 2001;20:817-29.

41. Farjo LA, Glick JM, Sampson TG. Hip arthroscopy for acetabular labral tears. Arthroscopy. 1999;15:132-7.

42. Fitzgerald RH. Acetabular labrum tears: diagnosis and treatment. Clin Orthop. 1995;311:60-8.

43. Byers PD, Contepomi CA, Farkas TA. A post mortem study of the hip joint. Ann Rheum Dis. 1970;29:15-31.

44. Byrd JW. Labral lesions: an elusive source of hip pain case reports and literature review. Arthroscopy. 1996;12:603-12.

45. McCarthy JC, Noble P, Schuck M, Alusio FV, Wright J, Lee J. Acetabular and labral pathology. In: Early hip disorders. New York: Springer Verlag; 2003.

46. Lage LA, Patel JV, Villar RN. The acetabular labral tear: an arthroscopic classification. Arthroscopy. 1996;12:269-72.

47. Santori N, Villar RN. Acetabular labral tears: results of arthroscopic partial limbectomy. Arthroscopy. 2000;16(1):11-5.

48. Hase T, Ueo T. Acetabular labral tear: arthroscopic diagnosis and treatment. Arthroscopy. 1999;15(2):138-41.

49. Ikeda T, Awaya G, Suzuki S, et al. Torn acetabular labrum in young patients. Arthroscopic diagnosis and management. J Bone Joint Surg Br. 1988;70:13-6.

50. Klaue K, Durnin CW, Ganz R. The acetabular rim syndrome. A clinical presentation of dysplasia of the hip. J Bone Joint Surg Br. 1991;73(3):423-9.
51. O'Leary JA, Berend K, Vail TP. The relationship between diagnosis and outcome in arthroscopy of the hip. Arthroscopy. 2001;17:181-8.

52. Suenaga E, Noguchi Y, Jingushi S, Shuto T, Nakashima Y, Miyanishi K, et al. Relationship between the maximum flexioninternal rotation test and the torn acetabular labrum of a dysplastic hip. J Orthop Sci. 2002;7:26-32.

53. Mintz DN, Hooper T, Connell D, Buly R, Padgett DE, Potter HG. Magnetic resonance imaging of the hip: detection of labral and chondral abnormalities using noncontrast imaging. Arthroscopy. 2005;21:385-93.

54. Mason JB. Acetabular labral tears in the athlete. Clin Sports Med. 2001;20:779-90.

55. Leunig M, Casillas MM, Hamlet M, et al. Slipped capital femoral epiphysis: early mechanical damage to the acetabular cartilage by a prominent femoral metaphysic. Acta Orthop Scand. 2000;71:370-4.

56. Kelly BT, Weiland DE, Schenker ML, Philippon MJ. Arthroscopic labral repair in the hip: surgical technique and review of the literature. Arthroscopy. 2005;21:1496-504.

57. Philippon MJ, Martin RR, Kelly BT. A classification system for labral tears of the hip. Arthroscopy. 2005;21 suppl:e36. abstr.

58. Paterson I. The torn acetabular labrum; a block to reduction of a dislocated hip. J Bone Joint Surg [Br]. 1957;39-B(2):306-9.

59. Lieberman JR, Altchek DW, Salvati EA. Recurrent dislocation of a hip with a labral lesion: treatment with a modified Bankart-type repair. Case Report. J Bone Joint Surg. 1993;75(10):1524-7.

60. Rashleigh-Belcher HJC, Cannon SR. Recurrent dislocation of the hip with a "Bankart-type" lesion. J Bone Joint Surg. 1986;68(3):398-9.

61. Ganz R, Parvizi J, Beck M, Leunig M, Notzli H, Siebenrock KA. FAI: a cause for osteoarthritis of the hip. Clin Orthop Relat Res. 2003;417:112-20.

62. Beck M, Kalhor M, Leunig M, Ganz R. Hip morphology influences the pattern of damage to the acetabular cartilage: femoroacetabular impingement as a cause of early osteoarthritis of the hip. J Bone Joint Surg Br. 2005;87:1012-8.

63. Ito K, Minka MAII, Leunig M, Werlen S, Ganz R. Femoroacetabular impingement and the cam-effect: a MRI-based quantitative anatomical study of the femoral head-neck offset. J Bone Joint Surg Br. 2001;83:171-6.

64. Notzli HP, Wyss TF, Stoecklin CH, Schmid MR, Treiber K, Hodler J. The contour of the femoral head-neck junction as a predictor for the risk of anterior impingement. J Bone Joint Surg Br. 2002;84:556-60.

65. Ito K, Leunig M, Ganz R. Histopathologic features of the acetabular labrum in femoroacetabular impingement. Clin Orthop Relat Res. 2004;429:262-71.

66. Philippon MJ, Hip arthroscopy in the athlete. In: Operative arthroscopy. 3rd ed. Philadelphia: Lippincott Williams \& Wilkins; 2002.

67. Siebenrock KA, Schoeniger R, Gans R. Anterior femoro-acetabular impingement due to acetabular retroversion: treatment with periacetabular osteotomy. J Bone Joint Surg Am. 2003;85: 278-86.

68. Coleman SS. Congenital dysplasia and dislocation of the hip. St. Louis: Mosby; 1978.

69. Li PL, Ganz R. Morphologic features of congenital acetabular dysplasia: one in six is retroverted. Clin Orthop. 2003;416: 245-53.

70. Robertson DD, Essinger JR, Imura S, Kuroki Y, Sakamaki T, Shimizu T, et al. Femoral deformity in adults with developmental hip dysplasia. Clin Orthop. 1996;327:196-206.

71. Siebenrock KA, Wahab KH, Werlen S, Kalhor M, Leunig M, Ganz R. Abnormal extension of the femoral head epiphysis as a cause of cam impingement. Clin Orthop. 2004;418:54-60. 
72. Lavigne M, Parvizi J, Beck M, Siebenrock KA, Ganz R, Leunig M. Anterior femoroacetabular impingement, part I: techniques of joint preserving surgery. Clin Orthop. 2004;418:61-6.

73. Dorrell JH, Catterall A. The torn acetabular labrum. J Bone Joint Surg Br. 1986;68:400-3.

74. Lane NE, Lin P, Christiansen L, Gore LR, Williams EN, Hochberg MC, et al. Association of mild acetabular dysplasia with an increased risk of incident hip osteoarthritis in elderly white women: the study of osteoporotic fractures. Arthritis Rheum. 2000;43:400-4.

75. Hickman JM, Peters CL. Hip pain in the young adult: diagnosis and treatment of disorders of the acetabular labrum and acetabular dysplasia. Am J Orthop. 2001;30:459-67.

76. McCarthy JC, Lee JA. Acetabular dysplasia: a paradigm of arthroscopic examination of chondral injuries. Clin Orthop. 2002;405:122-8.

77. Wenger DE, Kendell KR, Miner MR, Trousdale RT. Acetabular labral tears rarely occur in the absence of bony abnormalities. Clin Orthop Relat Res. 2004;426:145-50.

78. Philippon MJ, Arthroscopy of the hip in the management of the athlete. In: Operative arthroscopy. 3rd ed. Philadelphia: Lippincott-Raven; 2003.

79. Bharam S, Draovitch P, Fu FH. Return to competition in pro athletes with traumatic labral tears of the hip. Presented at the meeting of the American Orthopaedic Society for Sports Medicine, Orlando, FL, June 2002

80. Bharam S, Fu FH, Philippon MJ. Hip arthroscopy in golfers: characteristic lesions. Presented at the annual meeting of the American Academy of Orthopaedic Surgeons. New Orleans, LA, March 2003.

81. Paterson I. The torn acetabular labrum; a block to reduction of a dislocated hip. J Bone Joint Surg Br. 1957;39:306-9.

82. Depaulis F, Cacchio A, Michelini O, et al. Sports injuries in the pelvis and hip: diagnostic imaging. Eur J Radiol. 1998;27 Suppl 1:S49-59.

83. Binningsley D. Tear of the acetabular labrum in an elite athlete. Br J Sports Med. 2003;37(1):84-8.

84. Byrd JWT. Lateral impact injury: a source of occult hip pathology. Clin Sports Med. 2001;20(4):801-16.

85. Rao J, Zhou YX, Villar RN. Injury to the ligamentum teres. Mechanism, findings, and results of treatment. Clin Sports Med. 2001;20(4):791-9.

86. Bharam S. Clinical evaluation of hip pain: indications and contraindications. Op Tech Orthop. 2005;15(3):175-6.

87. Janda V. Evaluation of muscular imbalance: rehabilitation of the spine. Baltimore: Lippincott Williams \& Wilkins; 1996. p. 97-112.

88. Byrd JW, Jones KS. Hip arthroscopy in the presence of dysplasia. Arthroscopy. 2003;19:1055-60.

89. O'Leary JA, Berend K, Vail TP. The relationship between diagnosis and outcome in arthroscopy of the hip. Arthroscopy. 2001;17(2):181-8.

90. Byrd JW, Jones KS. Prospective analysis of hip arthroscopy with 2-year follow-up. Arthroscopy. 2000;16:578-87.

91. Bache CE, Clegg J, Herron M. Risk factors for developmental dysplasia of the hip: ultrasonographic findings in the neonatal period. J Pediatr Orthop B. 2002;11(3):212-8.

92. Saw T, Villar R. Footballer's hip: a report of six cases. J Bone Joint Surg Br. 2004;86(5):655-8.

93. Bonnomet F, Lefèbvre Y, Clavert P, Gicquel P, Marcillou P, Katzner M, et al. Arthroscopic treatment of acetabular labrum lesions: a series of 12 patients with a 4-year follow-up. Rev Chir Orthop Reparatrice Appar Mot. 2000;86:787-93.

94. Philippon MJ. New frontiers in hip arthroscopy: the role of arthroscopic hip labral repair and capsulorrhaphy in the treatment of hip disorders. Instr Course Lect. 2006;55:309-16.
95. Leunig M, Beck M, Dora C. Femoroacetabular impingement: etiology and surgical concept. Op Tech Orthop. 2005;15:247-55.

96. Nelson MC, Lauerman WC, Brower AC, Wells JR. Avulsion of the acetabular labrum with intra-articular displacement. Orthopedics. 1990;13:889-91.

97. Givens-Heiss DL G, Krebs DE, Riley PO, Strickland EM, Fares $\mathrm{M}$, Hodge WA, et al. In vivo acetabular contact pressures during rehabilitation, part II: postacute phase. Phys Ther. 1992;72:700-5.

98. Eijer H, Myers SR, Ganz R. Anterior FAI after femoral neck fractures. J Orthop Trauma. 2001;15(7):475-81.

99. Garbuz DS, Masri BA, Haddad F, et al. Clinical and radiographic assessment of the young adult with symptomatic hip dysplasia. Clin Orthop Relat Res. 2004;418:18-22.

100. Czerny C, Hoffman S, Neuhold A, et al. Lesions of the acetabular labrum: accuracy of MR imaging and MR arthrography in detection and staging. Radiology. 1996;200:225-30.

101. Bruce W, Van Der Wall H, Storey G, Loneragan R, Pitsis G, Kannangara S. Bone scintigraphy in acetabular labral tears. Clin Nucl Med. 2004;29:465-8.

102. Byrd JWT, Jones K. Diagnostic accuracy of clinical assessment, magnetic resonance imaging, magnetic resonance arthrography, and intra-articular injection in hip arthroscopy patients. Am J Sports Med. 2004;32(7):1668-74.

103. Newberg A, Newman J. Imaging the painful hip. Clin Orthop. 2003;406:19-28.

104. Hodler J, Yu JS, Goodwin D, Haghighi P, Trudell D, Resnick D. MR arthrography of the hip: improved imaging of the acetabular labrum with histologic correlation. Am J Roentgenol. 1995;165: 887-91.

105. Cote KP, Brunet ME, Gansneder BM, et al. Effects of pronated and supinated foot postures on static and dynamic postural stability. J Athl Train. 2005;40(1):40-6.

106. Plötz GM, Brossmann J, Schünke M, Heller M, Kurz B, Hassenpflug J. Magnetic resonance arthrography of the acetabular labrum: Macroscopic and histological correlation in 20 cadavers. J Bone Joint Surg. 2000;82:426-32.

107. Studler U, Kalberer F, Leunig M, Zanetti M, Hodler J, Dora C, et al. MR Arthrography of the Hip: Differentiation between an Anterior Sublabral Recess as a Normal Variant and a Labral Tear. Radiology. 2008;249(3):947-54.

108. Chan YS, Lien LC, Hsu HL, Wan YL, Lee MS, Hsu KY, et al. Evaluating hip labral tears using magnetic resonance arthrography: a prospective study comparing hip arthroscopy and magnetic resonance arthrography diagnosis. Arthroscopy. 2005;21(10):1250.

109. Schmid MR, Nötzli HP, Zanetti M, Wyss TF, Hodler J. Cartilage lesions in the hip: diagnostic effectiveness of MR arthrography. Radiology. 2003;226:382-6.

110. Toomayan GA, Holman WR, Major NM, Kozlowicz SM, Vail TP. Sensitivity of MR arthrography in the evaluation of acetabular labral tears. Am J Roentgenol. 2006;186:449-53.

111. Dinauer PA, Murphy KP, Carroll JF. Sublabral sulcus at the posteroinferior acetabulum: a potential pitfall in MR arthrography diagnosis of acetabular labral tears. Am J Roentgenol. 2004;183:1745-53.

112. Faraj AA, Kumaraguru P, Kosygan K. Intra-articular bupivacaine hip injection in differentiation of co-arthrosis from referred thigh pain: a 10 year study. Acta Orthop Belg. 2003;69(6): 518-621.

113. Huffman GR, Safran M. Arthroscopic treatment of labral tears. Oper Tech Sports Med. 2002;10:205-14.

114. McCarthy JC. The diagnosis and treatment of labral and chondral injuries. Instr Course Lect. 2004;53:573-7.

115. Clohisy JC, Keeney JA, Schoenecker PL. Preliminary assessment and treatment guidelines for hip disorders in young adults. Clin Orthop Relat Res. 2005;441:168-79. 
116. Clohisy JC, McClure JT. Treatment of anterior FAI with combined hip arthroscopy and limited open osteoplasty. Iowa Orthop J. 2005;25:164-71.

117. Beck M, Leunig M, Parvizi J, Boutier V, Wyss D, Ganz R. Anterior femoroacetabular impingement: Part II: midterm results of surgical treatment. Clin Orthop Relat Res. 2004;418: $67-73$.

118. Ganz R, Gill TJ, Gautier E, Ganz K, Krugel N, Berlemann U. Surgical dislocation of the adult hip a technique with full access to the femoral head and acetabulum without the risk of avascular necrosis. J Bone Joint Surg Br. 2001;83:1119-24.

119. Byrd JW. Hip arthroscopy: the supine position. Clin Sports Med. 2001;20:703-31.

120. Dienst M, Kohn D. Hip arthroscopy. Minimal invasive diagnosis and therapy of the diseased or injured hip joint. Unfallchirurg. 2001;104:2-18.

121. Dienst M, Seil R, Gödde S, Brang M, Becker K, Georg T, et al. Hip arthroscopy without traction: in vivo anatomy of the peripheral hip joint cavity. Arthroscopy. 2001;17:924-31.

122. Byrd JWT, Pappas JN, Pedley MJ. Hip arthroscopy: an anatomic study of portal placement and relationship to the extra-articular structures. Arthroscopy. 1995;11:418-23.

123. Byrd JWT. Avoiding the labrum in hip arthroscopy. Arthroscopy. 2000;16:770-3.

124. Werlen S, Leunig M, Ganz R. Magnetic resonance arthrography of the hip in femoroacetabular impingement: technique and findings. Op Tech Orthop. 2005;15(3):191-203.

125. Byrd JWT. Hip arthroscopy for post-traumatic loose fragments in the young active adult: three case reports. Clin Sports Med. 1996;6(2):129-34.
126. Trousdale RT, Ekkernkamp A, Ganz R, Wallrichs SL. Periacetabular and intertrochanteric osteotomy for the treatment of osteoarthrosis in dysplastic hips. J Bone Joint Surg Am. 1995;77(1):73-85.

127. Zoltan DJ, Clancy WG Jr, Keene JS. A new approach to snapping hip and refractory trochanteric bursitis in athletes. Am J Sports Med. 1986;14(3):201-4.

128. Kim SJ, Choi NH, Kim HJ. Operative hip arthroscopy. Clin Orthop. 1998;353:156-65.

129. Dorfmann H, Boyer T. Arthroscopy of the hip: 12 years of experience. Arthroscopy. 1999;15:67-72.

130. Clarke MT, Arora A, Villar RN. Hip arthroscopy: complications in 1054 cases. Clin Orthop. 2003;406:84-8.

131. Funke EL, Munzinger U. Complications in hip arthroscopy. Arthroscopy. 1996;12:156-9.

132. Griffin DR, Villar RN. Complications of arthroscopy of the hip. J Bone Joint Surg [Br]. 1999;81:604-6.

133. Villar RN. Hip arthroscopy. Br J Hosp Med. 1992;47:763-6.

134. Potter BK, Freedman BA, Andersen RC, Bojescul JA, Kuklo TR, Murphy KP. Correlation of short form-36 and disability status with outcomes of arthroscopic acetabular labral debridement. Am J Sports Med. 2005;33:864-70.

135. Dirocco S, McCarthy J, Busconi B, Dick B, Flaherty K. Rehabilitation after hip arthroscopy. In: Early hip disorders. New York: Springer Verlag; 2003. 